\title{
ANÁLISE SOBRE A DIVULGAÇÃO DE PROVISÕES E PASSIVOS CONTINGENTES AMBIENTAIS NO VALOR DE MERCADO DAS EMPRESAS DE ALTO POTENCIAL POLUIDOR LISTADAS NA BOLSA DE VALORES
}

\author{
ANALYSIS ON THE DISCLOSURE OF ENVIRONMENTAL PROVISIONS AND CONTINGENT LIABILITIES IN THE \\ MARKET VALUE OF HIGH POLLUTING POTENTIAL COMPANIES LISTED ON THE STOCK EXCHANGE
}

\author{
Josiane Aparecida Cardoso de Souza ${ }^{1}$, Beatriz Cristina Ferreira Machado ${ }^{2 *}$, Rodolfo de \\ Souza Cunha $^{3}$, Mário César Fialho de Oliveira ${ }^{4}, \&$ Patricia Werneck Silva de Oliveira $^{5}$ \\ ${ }^{1}$ Universidade Federal de Minas Gerais - UFMG. ${ }^{2345}$ Faculdades Integradas de Cataguases - UNIS. \\ ${ }^{1}$ josisouzakta@hotmail.com ${ }^{2^{*}}$ beatriz.machado@alunos.unis.edu.br ${ }^{3}$ rodolfo.cunha@alunos.unis.edu.br \\ ${ }^{4}$ mariocesar@hotmail.com ${ }^{5}$ patricia.oliviera@professor.unis.br
}

\section{ARTIGO INFO.}

\section{Recebido em: 30.09.2021}

Aprovado em: 27.10.2021

Disponibilizado em: 16.11.2021

\section{Palavras-chave:}

Provisões e Passivos Contingentes Ambientais; Empresas Potencialmente Poluidoras; Valor de Mercado; Disclosure Ambiental.

\section{KEYWORDS:}

Environmental Provisions and Contingent Liabilities; Potentially Polluting Companies; Market value; Environmental Disclosure.

\section{*Autor Correspondente: Machado, B. C. F.}

\section{RESUMO}

Este trabalho objetivou analisar os impactos da divulgação de provisões e passivos contingentes ambientais no valor de mercado das empresas de alto potencial poluidor listadas na B3. Foram consideradas 34 empresas listadas na Bolsa de Valores, as quais conforme Lei no 10.165/2000 que se refere a Política Nacional do Meio Ambiente, pertencem ao grupo de alto impacto poluidor. Para este estudo realizou-se uma análise de conteúdo para identificar a divulgação de provisões e passivos contingentes ambientais no ano de 2020. Após, foi realizada uma análise descritiva para investigar a distribuição e o comportamento das variáveis, assim como a execução de uma regressão pelo MQO para verificar a hipótese de pesquisa. Para avaliar a ligação entre as variáveis, utilizou-se a correlação de Pearson. Entre a variável independente (DIVULG) e o Valor de Mercado, o resultado não apresentou significância estatística, portanto a hipótese inicial de que a divulgação de provisões e passivos contingentes ambientais repercute positivamente no valor de mercado das empresas de alto potencial poluidor listadas na B3, foi rejeitada, evidenciando que tal divulgação não reflete no valor de mercado destas empresas. A variável
Tamanho da Empresa denotou significância estatística, mostrando que maior o tamanho da empresa, reflete em maior o seu Valor de Mercado, e a variável Retorno sobre os ativos apresentou significância negativa com o Valor de Mercado. O endividamento não mostrou significância estatística, deste modo, não apresenta relevância para justificar o valor de mercado das empresas avaliadas.

\section{ABSTRACT}

This work aimed to analyze the impacts of the disclosure of environmental provisions and contingent liabilities on the market value of companies with high polluting potential listed on B3. A total of 34 companies listed on the Stock Exchange were considered, which, according to Law 10,165/2000, which refers to the National Environmental Policy, belong to the high polluting impact group. For this study, a content analysis was performed to identify the disclosure of environmental provisions and contingent liabilities in the year 2020. Afterwards, a descriptive analysis was performed to investigate the distribution and behavior of the variables, as well as the execution of a regression by the OLS to verify the research hypothesis. To assess the link between the variables, Pearson's correlation was used. Between the independent variable (DIVULG) and the Market Value, the result was not statistically significant, therefore the initial hypothesis that the disclosure of environmental provisions and contingent liabilities has a positive impact on the market value of companies with high polluting potential listed in B3, was rejected, showing that such disclosure does not reflect the market value of these companies. The Company Size variable denoted statistical significance, showing that the larger the company size reflects its Market Value more, and the Return on assets variable had negative significance with the Market Value. Indebtedness did not show statistical significance; thus, it is not relevant to justify the market value of the companies evaluated. 
Citação (APA): Souza, J. A. C., de, Machado, B. C. F., Cunha, R. de S., Oliveira, M. C. F., de, \& Oliveira, P. W. S., de. (2021). Análise sobre a divulgação de provisões e passivos contingentes ambientais no valor de mercado das empresas de alto potencial poluidor listadas na bolsa de valores. Brazilian Journal of Production Engineering, 7(5), 65-81.

\section{INTRODUÇÃO}

Com a severa redução dos recursos naturais, os problemas ambientais estão se tornando cada vez mais relevantes (Lu \& Li, 2020; Tang et al., 2020; Fondevila et al., 2019; Chen et al., 2019; Odoemelam \& Okafor, 2018). A preocupação mundial com o meio ambiente faz com que as empresas enfrentem a pressão tanto por parte de políticas ambientais (Zhang, Xing, \& Wang, 2020) como por pressão da sociedade (Bachman, Carneiro \& ESPEJO, 2013) para que medidas ambientalmente sustentáveis e sociais sejam tomadas a fim de reduzir os impactos no meio em que está inserida (Agyemang, 2021; Chen et al., 2019; Marcon, Medeiros \& Ribeiro, 2017; Porter \& Kramer, 2006).

Rover, Borba e Borgert (2008) afirmam que os "impactos causados pelas empresas ao meio ambiente refletem no seu mercado de atuação e na imagem da organização perante a opinião pública". Dentre os diversos impactos ambientais ocasionados por empresas pode-se citar o descarte incorreto dos resíduos (Jaques et al., 2021), o desabamento de barragens (Carvalho \& Corteletti, 2021), a contaminação do solo, lagos, rios e mares (Lopes, 2020). Os impactos são catalogados de segundo o anexo VIII da Lei 10.165/2000 - determina sobre a Política Nacional do Meio Ambiente (PNMA) - podendo ser pequenos, médios e altos dependendo dos riscos potenciais oferecidos na atividade econômica de cada empresa; sendo os empreendimentos de maior impacto o objeto de estudo, para o presente artigo.

Com o propósito de divulgar informações relacionadas aos impactos ambientais gerados pelas atividades fabris, as empresas utilizam o disclosure ambiental (Solikhah, Maulina, \& Ntim, 2021). É uma técnica comum utilizada pelas empresas com a finalidade de transmitir suas informações financeiras ambientais aos stakeholders através de relatórios específicos regulares (Zhang, Xing, \& Wang, 2020, Lu \& Li, 2020; Pien 2020; Tzouvanas et al., 2020). Segundo Nunes (2021), a contabilidade ambiental se tornou uma avaliação do patrimônio ambiental, oferecendo aos interessados divulgações sobre acontecimentos ambientais que causem modificações no patrimônio.

Solikhah, Maulina e Netim (2021) afirmam que o sucesso de uma organização é determinado principalmente por três fatores: a rentabilidade, a qualidade e a responsabilidade ambiental. Por conseguinte, as empresas começaram a incluir a questão ambiental em seus relatórios, a investir em medidas que visem a redução dos impactos ocasionadas por suas atividades fabris e a empregar programas de gestão ambiental (Rover, Borba, \& Borget, 2008). Se tratando de contabilidade de característica ambiental, têm-se Provisões, Passivos Contingentes e Ativos Contingentes (CPC 25), difundido pelo Comitê de Pronunciamentos Contábeis (CPC) em 2009 e deliberado mediante a aprovação da Comissão de Valores Mobiliários (CVM n ${ }^{\circ}$ 594/09) ao qual estabelece sua valorização para corporações abertas. O Instituto Brasileiro de Contadores (IBRACON, 1996), entidade que representa auditores independentes, também recomenda a divulgação ambiental tanto no ativo quanto no passivo ambiental.

O CPC 25 tem por finalidade determinar que sejam empregados critérios de apuração e bases de medição adequado as provisões e a passivos e ativos contingentes e que esteja sendo divulgada informações suficientes nas notas explicativas possibilitando que os usuários

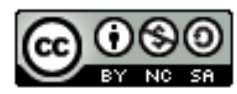



bolsa de valores. Brazilian Journal of Production Engineering, 7(5), 65-81.

compreendam a sua natureza, oportunidade e valor. Se a organização é qualificada no setor econômico com potencial poluidor alto, haverá uma associação positiva entre o valor de mercado e a divulgação de provisões e passivos contingentes (Bewley, 1998), visto que esta sofre mais com a opressão social em função do nível de divulgação (Nossa, 2002). Autores como Iatridis (2013) e Clarkson et al. (2013) verificaram que o disclosure ambiental afeta positivamente os resultados da empresa, principalmente quando há maior divulgação.

Diante disso, este estudo tem como objetivo de avaliar a relação entre empresas de alto potencial poluidor listadas na B3 e a divulgação de provisões e passivos contingentes ambientais no valor de mercado no ano de 2020. Levantando a seguinte hipótese de estudo: H1: A divulgação de provisões e passivos contingentes ambientais repercute positivamente no valor de mercado das empresas de alto potencial poluidor listadas na B3?

\section{REVISÃO DE LITERATURA}

\subsection{Custos e Investimentos Ambientais}

Com o decorrer dos anos, pode-se observar o crescente aumento da necessidade de se implementar a gestão ambiental nas organizações. Portanto, manter uma boa reputação e atender às expectativas de investidores, credores, fornecedores, clientes, funcionários, governo e sociedade são grandes desafios para muitas organizações (Miralles-Quirós et al., 2018). A atenção com as demandas ambientais permite às empresas uma vantagem estratégica, onde é possível usufruir dos benefícios obtidos por meio das ações sociais e ambientais praticadas corretamente. A partir da década de 1970, algumas grandes companhias começaram a demonstrar preocupação com questões sociais e ambientais e passaram a divulgar voluntariamente informações não financeiras (Ferreira et al., 2016).

Conforme Seifert (2011), a preservação do meio ambiente converteu-se em um dos fatores de maior influência dos anos 90 e da primeira década de 2000. As empresas começaram a evidenciar soluções e possibilidades para alcançar o desenvolvimento sustentável e simultaneamente aumentar a lucratividade de seus negócios. Segundo Rezaee (2016) no princípio do século XXI, após escândalos abrangendo grandes companhias globais, desastres ambientais e agravamento de problemas sociais, muitos gestores começaram a observar que a Sustentabilidade Empresarial (SE) é uma condição imprescindível para a melhoria da imagem das organizações

O Instituto Brasileiro de Contadores (Ibracon, 1996), através da Norma e Procedimento de Auditoria NPA 11 sobre Balanço e Ecologia, recomenda que tanto no ativo como no passivo ambiental, os valores de investimentos em meio ambiente fossem evidenciados em títulos contábeis específicos, identificando o ativo imobilizado ambiental, estoques ambientais, passivos ambientais, entre outros. O Ibracon (1996) recomenda também a evidenciação ambiental em:

Nota informativa que demonstre a sua posição ambiental, comunicando a política ambiental adotada, valor dos investimentos em ativos fixos e diferidos ambientais e critérios de amortização/depreciações, despesas ambientais debitadas ao resultado do exercício, passivo contingente e cobertura, se houve, de seguros, [...].

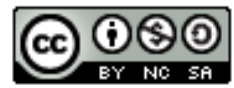



bolsa de valores. Brazilian Journal of Production Engineering, 7(5), 65-81.

Plumlee et al. (2015) fizeram um estudo que buscou evidenciar as ligações entre a qualidade das divulgações ambientais voluntárias e o valor da empresa, em que questionaram a ligação entre o valor das organizações no disclosure ambiental no preço das ações, no fluxo de caixa e no custo de capital.

Os investidores podem considerar as empresas ambientalmente responsáveis como possibilidades mais atrativas para investimento, com base no desenvolvimento geral em seu desempenho (Brizolla \& Klann, 2019).

\subsection{Evidenciação de Provisões e Passivos Contingentes}

A declaração do CPC 25 tem o propósito de definir que sejam empregados critérios de identificação e bases de mensuração adequadas às provisões, passivos e ativos contingentes e que seja feita a publicação em notas explicativas destinada aos usuários para que compreendam sua qualidade, natureza e seu valor.

Assim como contingências e provisões, a evidenciação é também de suma importância no cenário da disseminação de informações contábeis e financeiras. Diversos estudos já abordaram esse tema devido a sua relevância, com a finalidade de amenizar os riscos de assimetria de informação (Leite, 2018).

O Pronunciamento Conceitual Básico CPC 00 R2 (2019) afirma que os passivos são "uma obrigação presente da entidade de transferir um recurso econômico como resultado de eventos passados". Além disso, a Estrutura Conceitual salienta a necessidade de que a entidade possua uma obrigação presente como característica essencial para existência de um passivo. Rosa e Souza (2017) argumentam que os passivos contingentes ou também denominados de contingências passivas se referem a possíveis obrigações que ainda não se tem um compromisso presente e a organização não tem domínio das ações que culminaram o seu desfecho, além disso, esses passivos são interpretados como obrigações presentes em que não se tem a confiabilidade necessária para estabelecer o seu montante final com precisão.

Segundo Montoto (2018), o termo provisão se refere a um "passivo de prazo ou valor incerto", também definido pelo CPC 25. Segundo (Silva, Carraro, \& Silva, 2014) a provisão é um passivo, mas é necessário que seja diferenciada dos demais. O principal fator para essa diferenciação é a incerteza a com relação ao prazo ou valor a ser desembolsado para liquidação dessa possível obrigação (Silva, Carraro, \& Silva, 2014).

Conforme afirmam Plastina e Silveira (2017) “A provisão é uma forma da empresa se preparar para futuros desembolsos, gerados por obrigações passadas, no qual não é possível definir com exatidão a data e o valor futuro".

Os passivos contingentes ambientais, segundo o CPC 25, se distinguem em dois tipos de obrigações: a legal e a informal. A obrigação legal provém de contrato explícito ou implícito, por legislação ou por outra ação da lei, como por exemplo, as penalidades ou os custos da imposição de realizar a descontaminação ou recuperação de áreas a tingidas por ação da empresa. A obrigação informal resulta de ações da organização em que o evento (que pode suceder de práticas passadas, de políticas públicas ou de declaração atual da entidade) indica

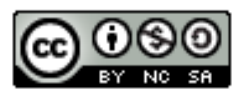


Citação (APA): Souza, J. A. C., de, Machado, B. C. F., Cunha, R. de S., Oliveira, M. C. F., de, \& Oliveira, P. W. S., de. (2021). Análise sobre a divulgação de provisões e passivos contingentes ambientais no valor de mercado das empresas de alto potencial poluidor listadas na bolsa de valores. Brazilian Journal of Production Engineering, 7(5), 65-81.

expectativas válidas de que a entidade cumprirá certas responsabilidades perante terceiros (Leal et al., 2015 apud Nascimento, 2018).

\subsection{Disclosure Ambiental}

Os diferentes grupos sociais, como fornecedores, clientes, parceiros empresariais e a própria comunidade, têm exigido mudanças nas organizações no que se refere às práticas socioambientais, o que gera reflexos em sua gestão e na forma com que divulgam sua influência com o ambiente. Sendo assim, nota-se que as empresas aumentam a busca pelo disclosure ambiental (Rover et al., 2012).

Rosa et al (2009) complementam expondo que o disclosure ambiental é composto por um conjunto de métodos usados pelas entidades para divulgar suas ações com a natureza, visando apresentar o que e como a empresa está se comportando em relação aos recursos naturais. Além disso, segundo os autores, qualifica-se por externar elementos financeiros e não financeiros decorrentes do vínculo entre a organização e o meio ambiente.

No Brasil, não há regulamento para o disclosure ambiental, logo, a divulgação realizada pelas empresas apresenta-se como espontânea. As Leis n. 6.404/76 e n. 11.638/07 não possuem especificidades para a divulgação desses aspectos. Contudo, o Parecer de Orientação n. 15/87 da Comissão de Valores Mobiliários (CVM), a Norma e Procedimento de Auditoria n. 11 do Instituto dos Auditores Independentes do Brasil (IBRACON) e a Resolução n. 1.003/04 do Conselho Federal de Contabilidade (CFC) apresentam instruções para que seja feita a divulgação das informações ambientais (Beuren, Santos, \& Gubiani, 2013).

Conforme Costa et al (2018) a divulgação de informações voluntárias tem se intensificado, no que se refere ao disclosure de informações sociais e ambientais, sendo evidenciada como um tema de grande importância, principalmente pelas iniciativas de organismos nacionais e internacionais, que têm debatido recorrentemente sobre questões relacionadas à sustentabilidade.

Como base para este estudo, foi revisitado o trabalho de Silva, Nascimento Júnior, Araújo (2018), ao qual verificou se a hipótese de que a divulgação de provisões e passivos contingentes ambientais poderia refletir de maneira positiva no valor de mercado das empresas altamente poluidoras que são apresentadas na B3. Os dados foram compilados no Brasil no intervalo de 2011 a 2014 e utilizou a regressão dos Métodos Mínimos Quadrados Ordinários (MQO) com dados em painel. Seus resultados apontaram significância estatística entre as variáveis valor de mercado e tamanho da empresa, indicando que quanto maior a empresa maior o seu valor de mercado, e entre valor de mercado e retorno sobre ativo. Contudo, não houve significância estatística entre a divulgação e o valor de mercado, fazendo com que a hipótese fosse rejeitada, ou seja, a divulgação de provisões e passivos contingentes ambientais não necessariamente refletem no aumento do valor de mercado de empresas que são potencialmente poluidoras citadas na B3.

Além das pesquisas já citadas na revisão de literatura, com o intuito de enfatizar os estudos anteriores acerca do disclosure de informações socioambientais, o quadro 1 apresenta um breve resumo de alguns estudos. 
Citação (APA): Souza, J. A. C., de, Machado, B. C. F., Cunha, R. de S., Oliveira, M. C. F., de, \& Oliveira, P. W. S., de. (2021). Análise sobre a divulgação de provisões e passivos contingentes ambientais no valor de mercado das empresas de alto potencial poluidor listadas na bolsa de valores. Brazilian Journal of Production Engineering, 7(5), 65-81.

Quadro 1. Estudos sobre a temática disclosure verde

\begin{tabular}{|c|c|}
\hline Descrição/Resultados & Autores \\
\hline $\begin{array}{l}\text { O artigo possui o objetivo de averiguar as informações ambientais disponíveis nos sites das } \\
\text { empresas e da Bolsa de Valores de São Paulo (BOVESPA), do setor de Papel e Celulose, e } \\
\text { percebeu que a falta de homogeneidade na elaboração dos relatórios divulgados dificulta a } \\
\text { interpretação das informações. }\end{array}$ & $\begin{array}{l}\text { Costa e } \\
\text { Marion } \\
(2007)\end{array}$ \\
\hline $\begin{array}{l}\text { A finalidade do estudo foi verificar as informações ambientais divulgadas voluntariamente por } \\
\text { empresas brasileiras, através da análise de conteúdo das DFP's do ano 2006. Em decorrência do } \\
\text { estudo constatou-se que a maior parte das informações ambientais é declarativa, do tipo } \\
\text { positiva, situada no Relatório da Administração e não auditada. }\end{array}$ & $\begin{array}{l}\text { Rover et al. } \\
\quad(2008)\end{array}$ \\
\hline $\begin{array}{l}\text { O intuito da pesquisa foi destacar os fatores que evidenciam o nível de disclosure voluntário de } \\
\text { empresas abertas no Brasil. observou-se que as variáveis Setor, Origem do Controle e Q de } \\
\text { Tobin são significativas para explicar o disclosure socioambiental. }\end{array}$ & $\begin{array}{l}\text { Murcia e } \\
\text { Santos } \\
(2009)\end{array}$ \\
\hline $\begin{array}{l}\text { O estudo ressaltou o disclosure ambiental voluntário, como sendo de suma importância para a } \\
\text { responsabilidade social das organizações. Nos resultados, o disclosure ambiental foi expressivo } \\
\text { quanto à atribuição de valor da firma, o que aponta sua função perante às estratégias ambientais } \\
\text { da gestão, conseguindo assim uma relação positiva com o custo de capital. }\end{array}$ & $\begin{array}{c}\text { Clarkson et } \\
\text { al. (2013) }\end{array}$ \\
\hline $\begin{array}{l}\text { A pesquisa verificou a relação entre o valor de mercado (mensurado pelo Q de Tobin) e a } \\
\text { divulgação voluntária de informações econômicas, sociais e ambientais em relatórios das } \\
\text { empresas listadas na BM\&FBOVESPA, no período de } 2007 \text { a } 2011 \text {. Como consequência, } \\
\text { houve uma relação expressiva e positiva entre a divulgação voluntária econômica e o valor de } \\
\text { mercado das empresas. }\end{array}$ & $\begin{array}{l}\text { Sousa et al } \\
\quad(2014)\end{array}$ \\
\hline $\begin{array}{l}\text { A pesquisa avaliou a relação entre a qualidade das divulgações ambientais voluntárias e o valor } \\
\text { das empresas. observou-se que a qualidade ambiental está diretamente ligada com o valor } \\
\text { firma, seja por meio do fluxo de caixa, quanto pelo custo do capital próprio. }\end{array}$ & $\begin{array}{l}\text { Plumlee } e t \\
\text { al. (2015) }\end{array}$ \\
\hline $\begin{array}{c}\text { No estudo apuraram como a responsabilidade social corporativa ajuda o desempenho financeiro } \\
\text { e o papel mediador da vantagem competitiva, reputação e satisfação do cliente. As conclusões } \\
\text { mostraram que a relação entre a responsabilidade social e o desempenho existe diante de um } \\
\text { fator mediador, sendo este a reputação e vantagem competitiva. }\end{array}$ & $\begin{array}{l}\text { Saeidi } \text { et al. } \\
\quad(2015)\end{array}$ \\
\hline
\end{tabular}

Fonte: Autores (2021)

\section{METODOLOGIA}

\subsection{Seleção da amostra e período de análise}

A população deste estudo é representada por todas as organizações de capital aberto, pertencentes a setores de alto impacto ambiental, listadas na BM\&FBovespa no ano de 2020. Para determinar o porte de cada empresa, recorreu-se o Anexo VIII da Lei $n^{\circ} 10.165 / 2000$, que dispõe sobre a Política Nacional do Meio Ambiente, o mesmo qualifica as atividades econômicas das empresas em pequeno, médio e alto impacto ambiental. A amostra compreende 34 empresas listadas na B3 e que pertencem ao grupo de alto potencial poluidor. O quadro 2 demonstra as empresas selecionadas para a pesquisa, enquadradas aos setores da B3 em relação ao Anexo VIII da Lei ${ }^{\circ} 10.165 / 2000$. 
Citação (APA): Souza, J. A. C., de, Machado, B. C. F., Cunha, R. de S., Oliveira, M. C. F., de, \& Oliveira, P. W. S., de. (2021). Análise sobre a divulgação de provisões e passivos contingentes ambientais no valor de mercado das empresas de alto potencial poluidor listadas na bolsa de valores. Brazilian Journal of Production Engineering, 7(5), 65-81.

Quadro 2. Classificação setorial quanto ao alto impacto ambiental

\begin{tabular}{|c|c|c|c|c|}
\hline \multirow{2}{*}{ SETOR ECONÔMICO } & \multirow{2}{*}{ SUBSETOR } & \multirow{2}{*}{ SEGMENTO } & \multicolumn{2}{|c|}{ LISTAGEM } \\
\hline & & & CÓDIGO & EGMENTO \\
\hline \multirow[t]{13}{*}{$\begin{array}{l}\text { Petróleo, Gás e } \\
\text { Biocombustíveis }\end{array}$} & $\begin{array}{c}\text { Petróleo, Gás e } \\
\text { Biocombustiveis }\end{array}$ & Exploração, Refino e Distribuição & & \\
\hline & & 3R PETROLEUM & RRRP & NM \\
\hline & & COSAN & CSAN & NM \\
\hline & & DOMMO & DMMO & \\
\hline & & ENAUTA PART & ENAT & NM \\
\hline & & PET MANGUINH & RPMG & \\
\hline & & PETROBRAS & PETR & $\mathrm{N} 2$ \\
\hline & & PETROBRAS BR & BRDT & NM \\
\hline & & PETRORIO & PRIO & NM \\
\hline & & ULTRAPAR & UGPA & NM \\
\hline & & Equipamentos e Serviços & & \\
\hline & & LUPATECH & LUPA & NM \\
\hline & & OSX BRASIL & OSXB & NM \\
\hline \multirow[t]{32}{*}{ Materiais Básicos } & Mineração & Minerais Metálicos & & \\
\hline & & BRADESPAR & BRAP & $\mathrm{N} 1$ \\
\hline & & MMX MINER & MMXM & NM \\
\hline & & VALE & VALE & NM \\
\hline & Siderurgia e Metalurgia & Siderurgia & & \\
\hline & & GERDAU & GGBR & $\mathrm{N} 1$ \\
\hline & & GERDAU MET & GOAU & $\mathrm{N} 1$ \\
\hline & & SID NACIONAL & CSNA & \\
\hline & & USIMINAS & USIM & N1 \\
\hline & & Artefatos de Ferro e Aço & & \\
\hline & & MANGELS INDL & MGEL & \\
\hline & & PANATLANTICA & PATI & \\
\hline & & TEKNO & TKNO & \\
\hline & & Artefatos de Cobre & & \\
\hline & & PARANAPANEMA & PMAM & NM \\
\hline & Químicos & Petroquímicos & & \\
\hline & & BRASKEM & BRKM & $\mathrm{N} 1$ \\
\hline & & GPC PART & GPCP & \\
\hline & & Fertilizantes e Defensivos & & \\
\hline & & FER HERINGER & FHER & NM \\
\hline & & NUTRIPLANT & NUTR & MA \\
\hline & & Químicos Diversos & & \\
\hline & & CRISTAL & CRPG & \\
\hline & & UNIPAR & UNIP & \\
\hline & Madeira e Papel & Madeira & & \\
\hline & & DURATEX & DTEX & NM \\
\hline & & EUCATEX & EUCA & N1 \\
\hline & & Papel e Celulose & & \\
\hline & & IRANI & RANI & \\
\hline & & KLABIN S/A & KLBN & N2 \\
\hline & & MELHOR SP & MSPA & \\
\hline & & SUZANO S.A. & SUZB & NM \\
\hline
\end{tabular}


Citação (APA): Souza, J. A. C., de, Machado, B. C. F., Cunha, R. de S., Oliveira, M. C. F., de, \& Oliveira, P. W. S., de. (2021). Análise sobre a divulgação de provisões e passivos contingentes ambientais no valor de mercado das empresas de alto potencial poluidor listadas na bolsa de valores. Brazilian Journal of Production Engineering, 7(5), 65-81.

A partir da classificação e estratificação por segmento, foi utilizado o software Microsoft Excel® para organizar os dados das referidas empresas. Foram então coletadas as informações a partir das demonstrações financeiras padronizadas (DFP), nos websites das organizações, da Comissão de Valores Mobiliários e da BM\&FBovespa.

\subsection{Coleta e análise dos dados}

A princípio foi efetuada um estudo dos conteúdos das divulgações das empresas. Para isso, foram analisadas as notas explicativas disponibilizadas nos sites da B3, nos websites das organizações, nas seções Relacionamento com Investidores (RI), websites da BM\&FBovespa e da Comissão de Valores Mobiliários, com a intenção de verificar as informações sobre provisões e passivos contingentes divulgados pelas empresas estudadas, no ano de 2020.

O método utilizado para verificação do conteúdo analisado foi equivalente ao de Nascimento Júnior (2018), no qual imputou o número 0 para os valores não identificados nas notas explicativas, e o número 1 para aqueles valores que foram divulgados pelas organizações.

De acordo com o CPC 25 (2009), toda informação tem de ser divulgada pela organização, a não ser que seja algum item não obrigatório, quando não aplicável, a empresa deverá justificar o motivo. As outras variáveis, conforme apresentadas no Quadro 3, Valor de Mercado (VM), Endividamento (ENDIV), Retorno Sobre os Ativos (ROA) e Tamanho da Empresa (TAM), foram coletadas da base de dados da Economática, para analisar as informações relativas ao desempenho econômico-financeiro das empresas.

Quadro 3. Variáveis da pesquisa

\begin{tabular}{|c|c|c|c|c|c|}
\hline Var. & Tipo & Descrição & Cálculo & $\begin{array}{c}\text { Efeito } \\
\text { esperado }\end{array}$ & Referências \\
\hline VM & D & Valor de Mercado & $\begin{array}{c}\text { O número de ações da } \\
\text { empresa multiplicado } \\
\text { pelo seu preço. }\end{array}$ & & Nelling e Webb \\
DIVULG & I & $\begin{array}{c}\text { Divulgação de informações sobre } \\
\text { provisões e passivos contingentes } \\
\text { ambientais conforme CPC } 25 .\end{array}$ & $\begin{array}{c}\text { (0) para as empresas que } \\
\text { nas que divulgaram. }\end{array}$ & + & $\begin{array}{c}\text { Fonteles } \text { et al. } \\
(2012) ; \text { Rufino e } \\
\text { Machado (2015) }\end{array}$ \\
\hline ROA & $\mathrm{C}$ & Retorno sobre os Ativos & $\begin{array}{c}\text { Lucro Líquido/ Ativo } \\
\text { Total }\end{array}$ & + & $\begin{array}{c}\text { Stulz (1990); } \\
\text { Durand (1959) }\end{array}$ \\
\hline ENDIV & $\mathrm{C}$ & Endividamento & Exigível Total/PL & + & $\begin{array}{c}\text { Murcia e Santos } \\
(2009) ; \text { Rufino e } \\
\text { Monte (2014) }\end{array}$ \\
\hline
\end{tabular}

Legenda: Var. - Variáveis; D - Dependente; I - Independente; C - Controle; CPC - Comitê de Pronunciamentos Contábeis; PL - Patrimônio Líquido.

Fonte: Base de dados Economática ${ }^{\circledR}$.

Esta pesquisa observa o possível efeito em uma variável dependente o Valor de Mercado (VM) por empresas listadas na B3, a variável independente é a Divulgação de Provisões e Passivos Contingentes Ambientais de acordo com o CPC 25 (DIVULG), e as variáveis Retorno sobre o Ativo (ROA), o Tamanho da Empresa (TAM) e o Endividamento (ENDIV) são as variáveis de 

bolsa de valores. Brazilian Journal of Production Engineering, 7(5), 65-81.

controle. Em relação aos dados referentes ao ano de 2020, ou seja, dez anos após a publicação do CPC 25.

Para aferir a hipótese de pesquisa foi aplicada uma regressão pelo Método de Mínimos Quadrados Ordinários com a estruturação de dados em painel correspondente ao ano de 2020. O modelo econométrico empregado, foi baseado no estudo de Silva, Nascimento Júnior, Araújo (2018) e é mostrado a seguir na equação 1:

$$
\text { VM }=\alpha+\beta 1 \text { DIVULG it }+\beta 2 \text { ROA it }+\beta 3 \text { ENDIV it }+\beta 4 \text { TAM it }+\varepsilon
$$

A variável dependente é Valor de Mercado (VM), a variável independente é a Divulgação de Provisões e Passivos Contingentes Ambientais de acordo com o CPC 25 (DIVULG), e as variáveis Retorno sobre o Ativo (ROA), o Endividamento (ENDIV), o Tamanho da Empresa (TAM) são as variáveis de controle.

\section{RESULTADOS E DISCUSSÃO}

Uma análise descritiva é feita para investigar a distribuição e o comportamento das variáveis. Após, foi analisado o resultado da regressão MQO com a intenção de examinar as hipóteses de pesquisa e detectar se existe relação entre o valor de mercado das empresas e a DIVULG (divulgação de provisões e de passivos contingentes ambientais) que são altamente poluentes contidas na B3.

\subsection{Análise descritiva}

Dentre as 34 empresas, 6 não realizaram a divulgação completa conforme CPC 25, recebendo, portanto, 0 e aquelas que divulgaram receberam 1. Os resultados da análise descritiva são mostrados na tabela 1, exceto para a variável DIVULG por ser dicotômica (categórica). As variáveis VM (4.11146) e ENDIV (8.83219) possuem dispersão elevada e ROA (0.89430) possui dispersão baixa à volta das médias. Isso pode ser confirmado com a amplitude, onde a diferença entre os valores máximo e mínimo de VM, ENDIV e ROA são 13.49048, 45.3235 e 5.4735 , respectivamente.

Tabela 1. Análise descritiva

\begin{tabular}{lccccc}
\hline Variável & Média & Desvio Padrão & Mediana & Mínimo & Máximo \\
\hline VM & 18.966 & 4.11146 & 19.4576 & 11.61092 & 25.1014 \\
ROA & -0.13912 & 0.8943 & 0.04683 & -5.13655 & 0.33695 \\
ENDIV & -0.56097 & 8.83219 & 1.40081 & -30.5281 & 14.7954 \\
TAM & 8.48971 & 2.29787 & 8.1552 & 4.18888 & 13.9798 \\
\hline
\end{tabular}

Fonte: Autores, 2021

O índice ROA apresentou média negativa (-0.13912), o que pode ser justificado pelo fato de $35.29 \%$ das empresas possuírem retorno sobre ativo negativo, 41,18\% apresentaram tal valor positivo, porém, entre 0 e 0.09 e somente $23,53 \%$ com intervalo entre 0.1 e 0.33 . O ENDIV também apresentou média negativa (-0.56097), mas diferentemente de ROA, apenas $26,47 \%$, ou seja, 9 empresas possuem endividamento negativo, contudo juntas somam -91,1021; enquanto os restantes somam 72,0298.

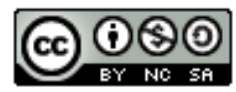



bolsa de valores. Brazilian Journal of Production Engineering, 7(5), 65-81.

Para avaliar o grau de relação entre as variáveis, foi utilizada a correlação de Pearson, que varia entre -1 e 1, onde o sinal negativo denota a associação da correlação (forte ou fraca) e o valor, a intensidade (Schober et al., 2018). Os valores da correlação de Pearson são mostrados na tabela abaixo.

Tabela 2. Correlação de Pearson

\begin{tabular}{cccccc}
\hline & VM & DIVULG & ROA & ENDIV & TAM \\
VM & 1 & 0,45 & 0,04 & $-0,05$ & 0,54 \\
DIVULG & & 1 & $-0,09$ & $-0,13$ & 0,54 \\
ROA & & & 1 & 0,03 & 0,30 \\
ENDIV & & & & 1 & $-0,06$ \\
TAM & & & & & 1 \\
\hline
\end{tabular}

Fonte: Autores, 2021

Pode-se observar que as correlações mais fortes são entre TAM e VM (0,54); TAM e DIVULG $(0,54)$, apontando que uma cresce a outra também cresce proporcionalmente e vice-versa. As correlações negativas entre variáveis como, por exemplo, entre DIVULG e ENDIV $(-0,13)$ e DIVULG e ROA $(-0,09)$ apontam associação inversa entre elas, enquanto uma variável aumenta, a outra diminui e vice-versa, e apesar de serem valores baixos, isso demonstra que existe alguma correlação entre elas. $\mathrm{O}$ valor de mercado possui maior correlação com as variáveis de divulgação de provisão e passivos contingentes ambientais e com o tamanho da empresa.

\subsection{Análise inferencial}

Para analisar a hipótese do estudo, de que a divulgação de provisões e passivos contingentes ambientais impacta de forma positiva no valor de mercado das empresas que possuem alto potencial poluidor na B3, utilizou-se a regressão dos Mínimos Quadrados Ordinários (MQO). A princípio foi realizado o teste de multicolinearidade através do Fator de Inflação da Variância (VIF) das variáveis TAM, DIVULG, ROA e ENDIV, apresentando valores iguais a 1,698; 1,$574 ; 1,222 ; 1,018$, respectivamente e média igual 1,378 . Tais valores indicam a não existência da colinearidade, uma vez que todos são menores que 10 (HAIR et al, 1995) (Tabela 3).

Tabela 3. Apuração da regressão para testar a hipótese

\begin{tabular}{ccccc} 
Variáveis & Coeficientes & Desvio Padrão & t & p-valor \\
\hline Intercepto & 2,4782 & 5,2993 & 0,47 & 0,64 \\
TAM & 7,0583 & 2,8663 & 2,46 & 0,02 \\
DIVULG & 1,957 & 2,0027 & 0,98 & 0,34 \\
ROA & $-0,3397$ & 0,7633 & $-0,45$ & 0,66 \\
ENDIV & 0,0116 & 0,0706 & 0,16 & 0,87 \\
\hline
\end{tabular}

Fonte: Autores, 2021

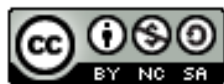



bolsa de valores. Brazilian Journal of Production Engineering, 7(5), 65-81.

Segundo o p-valor, a única variável que demonstrou significância estatística menor que 0,05 foi o tamanho da empresa $(0,02)$ com desvio padrão de 2,8663 e coeficiente igual a 7,0583. O coeficiente positivo indica a presença de uma relação positiva com a variável dependente VM, isto é, quanto maior o TAM maior é o VM da empresa. Resultados que vão de encontro ao dos autores Cunha e Ribeiro (2007).

A variável ROA foi o único que apresentou coeficiente negativo, ao qual indica uma relação inversa com a variável VM, quanto maior o ROA menor o VM, porém esta não apresenta significância estatística (p-valor=0,66). Estudos como de Silva, Nascimento Júnior, Araújo (2018) também obtiveram coeficiente negativo entre ROA e VM, já Nogueira, Curi e Nuintin (2012) e Fonteles et al. (2012) encontraram coeficientes positivos, e afirmaram que o aumento do ROA da empresa fará com que os patrimônios dos sócios aumentem, podendo ser por meio de pagamento de dividendos ou autofinanciamento com a totalidade do capital. Assim, como nessa pesquisa, Lima, Lima e Neves Junior (2012) também não encontraram significância estatística entre ROA e VM.

A variável ENDIV apresentou o menor coeficiente, mas também é outra variável que não é estatisticamente significativa $(0,87)$, apontando que o nível de endividamento não é relevante para justificar o VM. Resultado este similar ao estudo de Silva, Nascimento Júnior, Araújo (2018), mas diferente ao de Stulz (1990) que verificou a existência de relação entre VM e ENDIV.

Por fim, a variável DIVULG apresentou coeficiente positivo, o que indicaria uma relação positiva entre ela e VM, mas tal variável também não foi estatisticamente significativa (pvalor=0,34). Com isso, a hipótese de que a divulgação de provisões e passivos contingentes ambientais poderia refletir positivamente no valor de mercado das empresas que se encontram na lista da B3, foi rejeitada. Resultado que corrobora com dos autores Silva, Nascimento Júnior e Araújo (2018), mas contrário ao do autor Bewley (1998) que verificou uma associação positiva entre VM e DIVULG.

Com relação ao modelo, este apresentou um coeficiente de determinação igual a 25,50\% (R2), significando que o modelo de regressão é capaz de explicar 25,50\% da dispersão dos dados em relação ao modelo da média. Em outras palavras, esse valor demonstra o poder explicativo das disparidades detectadas no Valor de Mercado que as variáveis do modelo possuem conjuntamente.

\section{CONSIDERAÇÕES FINAIS}

O objetivo deste estudo foi analisar os impactos da divulgação de provisões e de passivos contingentes ambientais no valor de mercado das empresas de alto potencial poluidor listadas na B3. A amostragem desta pesquisa refere-se às empresas consideradas de alto potencial poluidor listadas na B3, de acordo com o Anexo VIII da Lei no 10.165/2000, que dispõe sobre a Política Nacional do Meio Ambiente.

Através dos resultados, pode-se observar que as maiores correlações positivas estão relacionadas ao tamanho da empresa com a divulgação e com o valor de mercado (ambas 0,54), bem como o valor de mercado e a divulgação que apresentaram correlação de 0,45 . Essas 
Citação (APA): Souza, J. A. C., de, Machado, B. C. F., Cunha, R. de S., Oliveira, M. C. F., de, \& Oliveira, P. W. S., de. (2021). Análise sobre a divulgação de provisões e passivos contingentes ambientais no valor de mercado das empresas de alto potencial poluidor listadas na bolsa de valores. Brazilian Journal of Production Engineering, 7(5), 65-81.

correlações mostram que uma influência a outra positivamente, em que a medida que uma variável aumenta a outra também aumenta. As correlações negativas acontecem entre divulgação e endividamento (-0,13); e divulgação e retorno sobre ativos $(-0,09)$, apontando que à medida que uma aumenta a outra diminui e vice-versa.

A regressão MQO apresentou coeficiente negativo para o retorno sobre o ativo em relação ao valor de mercado e positivo para o restante, contudo a significância estatística foi apenas no tamanho da empresa em relação ao valor de mercado, as mesmas nas quais apresentaram uma das maiores correlações.

Como a significância estatística foi somente entre o retorno sobre o ativo em relação ao valor de mercado, a hipótese sugerida para o estudo de que a divulgação de provisões e passivos contingentes ambientais reflete positivamente no valor de mercado das empresas com alto impacto poluidor listadas na B3, foi rejeitada. Apontando que a divulgação de provisões e passivos contingentes ambientais não é vista como uma informação com relevância para a precificação das ações e que o mercado não valoriza tal evidenciação dessas informações, desse modo, não é levado em consideração na tomada de decisões sobre investimentos.

Contudo, nota-se que frente aos desastres ambientais catastróficos ocorridos no Brasil, como o incidente de Brumadinho e Mariana, há uma maior pressão tanto das autoridades fiscalizadoras quanto da sociedade civil para que as empresas em geral, não só do ramo de mineração tenham maior transparência e preocupação com a divulgação de suas informações ambientais no que tange não apenas os programas de proteção e preservação ambiental, mas sim de ações sustentáveis como utilização de fontes de energia renovável, reciclagem e redução de poluição e degradação de uma forma geral.

Com base nesses dados, provavelmente, os investidores concordam que as empresas ao realizarem a divulgação das provisões e passivos contingentes ambientais estão cumprindo com sua obrigação. Outro ponto a ser observado, é com relação à visão de curto prazo do acionista em entender quais os efeitos da divulgação das provisões e passivos contingentes ambientais, que apesar de ser algo relevante em nossa atualidade, é visto como custos implícitos ao se realizarem.

No entanto, o presente estudo possui algumas limitações, uma delas seria a não divulgação de provisões e passivos contingentes ambientais referentes à algumas empresas no ano da pesquisa, tornando a amostra pequena. Observou-se também a imprecisão ao caracterizar a métrica utilizada para compor a variável DIVULG, a qual certifica se a empresa divulga ou não divulga as provisões e os passivos contingentes ambientais, e os poucos estudos com relação aos reflexos da divulgação de provisões e passivos contingentes ambientais no valor de mercado das empresas.

\section{REFERÊNCIAS}

Agyemang, A. O., Yusheng, K., Twum, A.K. et al., (2021). Trend and relationship between environmental accounting disclosure and environmental performance for mining companies listed in China. Environ Dev Sustain 23, 12192-12216. https://doi.org/10.1007/s10668-02001164-4

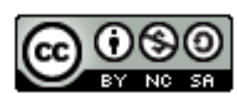


Citação (APA): Souza, J. A. C., de, Machado, B. C. F., Cunha, R. de S., Oliveira, M. C. F., de, \& Oliveira, P. W. S., de. (2021). Análise sobre a divulgação de provisões e passivos contingentes ambientais no valor de mercado das empresas de alto potencial poluidor listadas na bolsa de valores. Brazilian Journal of Production Engineering, 7(5), 65-81.

B3. (2020) Ações - Empresas Listadas, 2020. Recuperado de http://www.b3.com.br/pt br/produtos-e-servicos/negociacao/renda-variavel/empresaslistadas.htm

B3. (2021) B3 divulga a 16 ${ }^{\mathrm{a}}$ carteira do ISE B3 - B3, 2021. Recuperado de http://www.b3.com.br/pt_br/noticias/indice-de-sustentabilidade-empresarial-

8AE490C8761BBCDB01761EA822C50302.htm\#: :text=S\%C3\%A3o\%20convidadas\%20pa ra\%20o\%20processo,sendo\%2045\%20na\%20categoria\%20Eleg\%C3\%ADvel.\&text=\%E2\%8 0\%9CA\%20B3\%20tem\%20um\%20papel,boas\%2

B3. (2019) O que é o ISE B3. ISE B3, 2019. Recuperado de http://iseb3.com.br/o-que-e-o-ise

Bachmann, R. K., Carneiro, L. M., \& Espejo, M. M. S. B. (2013). Evidenciação de informações ambientais: proposta de um indicador a partir da percepção de especialistas. 7(17), 36-47.

Beuren, I. M., Santos, V. D., \& Gubiani, C. A (2013). Informações ambientais evidenciadas no relatório da administração pelas empresas do setor elétrico listadas no ISE. BASE - Revista de $\begin{array}{lllll}\text { Administração } \quad e \quad C o n t a b i l i d a d e & d a & \text { UNISINOS, } & \text { 10(1), } & \text { 55-68. }\end{array}$ https://doi.org/10.1016/j.rege.2016.07.002

Bewley, K. (1998). The economic consequences of financial reporting standards: the market valuation of environmental liabilities. Thesis (Doctor of Philosophy in Accounting). University of Waterloo, National Library of Canadá, Waterloo, Ontário, Canada.

Brasil (2021). Lei $n^{\circ} 10.165$, de 27 de dezembro de 2000. Altera a Lei ${ }^{\circ} 6.938$, de 31 de agosto de 1981, que dispõe sobre a Política Nacional do Meio Ambiente, seus fins e mecanismos de formulação e aplicação, e dá outras providências. Recuperado de http://www.planalto.gov.br/ccivil_03/Leis/L10165.htm

Brasil. Lei $\mathrm{n}^{\mathrm{o}} 10.165$, de 27 de dezembro de 2000. Altera a Lei $\mathrm{n}^{\circ} 6.938$, de 31 de agosto de 1981, que dispõe sobre a Política Nacional do Meio Ambiente, seus fins e mecanismos de formulação e aplicação, e dá outras providências. Recuperado de http://www.planalto.gov.br/ccivil_03/Leis/L10165.htm

Brizolla, M. M., \& Klann, R. (2019). Influence of environmental expenditures and environmental disclosure in the quality of accounting information. Environmental Quality Management. 28. https://doi.org/10.1002/tqem.21632

Carvalho, G. B., \& Corteletti, R. C (2021). Proposta metodológica para previsão de impactos decorrentes de acidentes com barragens de rejeito. Engenharia Sanitaria e Ambiental, [S.L.], 26(3), 525-534. FapUNIFESP (SciELO). http://dx.doi.org/10.1590/s1413-415220190061

Chen, Y.; Wang, Z., \& Zhong, Z. (2019). CO2 emissions, economic growth, renewable and non-renewable energy production and foreign trade in China, Renewable Energy, Elsevier, 131(C), 208-216. https://doi.org/10.1016/j.renene.2018.07.047

Clarkson, P., Fang, X., LI, Y., \& Richardson, G (2013). The relevance of environmental disclosure: are such disclosures incrementally informative? Journal of Accounting and Public Policy, 32, 410-43. https://doi.org/10.1016/j.jaccpubpol.2013.06.008

Comissão de Valores Mobiliários [CVM]. (1987). Parecer de orientação $\mathrm{n}^{\circ}$ 15, de 28 de dezembro de 1987.

Comitê de Pronunciamentos Contábeis (2009). Pronunciamento Técnico CPC 25 - Provisões, passivos contingentes e ativos contingentes. Brasília. Recuperado de http://static.cpc.aatb.com.br/Documentos/304 CPC 25 rev\%2013.pdf

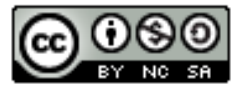


Citação (APA): Souza, J. A. C., de, Machado, B. C. F., Cunha, R. de S., Oliveira, M. C. F., de, \& Oliveira, P. W. S., de. (2021). Análise sobre a divulgação de provisões e passivos contingentes ambientais no valor de mercado das empresas de alto potencial poluidor listadas na bolsa de valores. Brazilian Journal of Production Engineering, 7(5), 65-81.

Comitê de Pronunciamentos Contábeis (2019). Pronunciamento Técnico CPC 00 (R2) Estrutura Conceitual para Elaboração e Divulgação de Relatório Contábil-Financeiro. Brasília, 2019. Recuperado de http://static.cpc.aatb.com.br/Documentos/573_CPC00(R2).pdf

Comitê de Pronunciamentos Contábeis [CPC] (2009). CPC-25: Provisões, passivos contingentes e ativos contingentes. Recuperado de http://www.cpc.org.br/CPC/DocumentosEmitidos/Pronunciamentos/Pronunciamento?Id=56

Comitê de Pronunciamentos Contábeis. Pronunciamento Técnico CPC 00 (R2) - Estrutura Conceitual para Elaboração e Divulgação de Relatório Contábil-Financeiro. Brasília, 2019. Recuperado de http://static.cpc.aatb.com.br/Documentos/573_CPC00(R2).pdf

Comitê de Pronunciamentos Contábeis. Pronunciamento Técnico CPC 25 - Provisões, passivos contingentes e ativos contingentes. Brasília, 2009. Recuperado de http://static.cpc.aatb.com.br/Documentos/304_CPC_25_rev\%2013.pdf

Conselho Federal de Contabilidade (CFC). (2004). Resolução CFC n ${ }^{\circ} 1.003 / 04$. Aprova a NBC T 15 - Informações de natureza social e ambiental. Brasília, DF.

Conselho Federal de Contabilidade [CFC]. (2004). Resolução CFC nº 1.003/04. Aprova a NBC T 15 - Informações de natureza social e ambiental. Brasília, DF.

Costa, I. L. S., Correia, T. S., Paulo, E., \& Lucen, W. G. L. (2018) Impacto do Disclosure Voluntário: valor da empresa e informações socioambientais nas companhias abertas. Contabilidade, Gestão e Governança, [S.L.], 21(2), 271-287. Revista Contabilidade Gestao e Governanca. http://dx.doi.org/10.21714/1984-3925_2018v21n2a7

Costa, R. S., \& Marion, J. C. (2007). A uniformidade na evidenciação das informações ambientais. Revista Contabilidade \& Finanças, 18(43), 20-33. Recuperado de http://www.revistas.usp.br/rcf/article/view/34212/36944

Cunha, J. V. A., \& Ribeiro, M. S. (2007). Divulgação voluntária de informações de natureza social: um estudo nas em presas brasileiras. Revista de Administração - Eletrônica, (1), 1-23.

Durand, D. (1959). The cost of capital, corporation finance, and the theory of investment: comment. American Economic Review, 4, 639-655

Ferreira, J. S., Rover, S., Ferreira, D. D. M, \& Borba, J. A. (2016) Informações Financeiras Ambientais: diferença entre o nível de disclosure entre empresas brasileiras. Revista de Educação e Pesquisa em Contabilidade (REPeC), Brasília, 10(1).

FIEMG [Brasil] (2019). A responsabilidade socioambiental e sua importância para os negócios: benefícios para o meio ambiente e para a sua empresa. Benefícios para o meio ambiente e para a sua empresa. Recuperado de https://www7.fiemg.com.br/noticias/detalhe/aresponsabilidade-socioambiental-e-sua-importancia-para-os-negocios

Fondevila, M. M., Moneva, J. M., \& Scarpellini, S. (2019). Divulgación ambiental y la interrelación de la ecoinnovación. El caso de las empresas españolas. Servicio de Publicaciones de la Universidad de Murcia. Revista de Contabilidad, [S.L.], 22(1), 73-87. http://dx.doi.org/10.6018/rc-sar.22.1.354321

Fonteles, I. V., Nascimento, C. P. S., Ponte, V. M. R., \& Rebouças, S. M. D. P. (2012). Determinantes da evidenciação de provisões e contingências por companhias listadas na BM\&FBOVESPA. In: Congresso USP de Controladoria e Contabilidade, 12, São Paulo. Anais... São Paulo: FEA/USP.

Hair, J. F., Jr., Anderson, R. E., Tatham, R. L., \& Black, W. C. (1995). Multivariate Data Analysis (3rd ed). New York: Macmillan. 
Citação (APA): Souza, J. A. C., de, Machado, B. C. F., Cunha, R. de S., Oliveira, M. C. F., de, \& Oliveira, P. W. S., de. (2021). Análise sobre a divulgação de provisões e passivos contingentes ambientais no valor de mercado das empresas de alto potencial poluidor listadas na bolsa de valores. Brazilian Journal of Production Engineering, 7(5), 65-81.

Iatridis, G. E. (2013). Environmental disclosure quality: evidence on environmental performance, corporate governance and value relevance. Emerging Markets Review, [S.L.], 14, 55-75. Elsevier BV. http://dx.doi.org/10.1016/j.ememar.2012.11.003

Ibracon - Instituto Brasileiro de Contadores. Normas e Procedimentos de Auditoria (1996). NPA 11 Balanço e Ecologia. Recuperado de http://www.ibracon.com.br/publicacoes/resultado.asp?identificador=223

Jaques, A. P., Freitas, D. P., Almada Resende, J. D. S., \& Silva Resende, J. G. O. (2021) Malefícios do descarte incorreto de resíduos e a importância da coleta seletiva juntamente com a reciclagem. Anais do Congresso de Pesquisa e Extensão do UNIPTAN, 5, 299-304. UNIPTAN, FUNDADESP.

Leite, J. R. (2018). Evidenciação de provisões e passivos contingentes (IAS 37/CPC 25): análise comparativa entre Brasil e França. Tese de doutorado. Curso de Finanças e Controladoria, São Paulo, SP, Brasil.

Lima, R. R., Lima, T. R., \& Neves Jr., I. J. (2011). Valor da Empresa e sua Relação com a estrutura de capital, rentabilidade: um estudo empírico das 1000 empresas melhores listadas na Revista Exame. In.: Simpósio de Gestão da Inovação Tecnológica, Resende - RJ. Anais... Resende: SEGeT. Recuperado de http://www.spell.org.br/documentos/ver/37846/valor-daempresa-e-sua-relacao-com-a-estrutura-de-capital--rentabilidade--um-estudo-empirico-das1000-empresas-melhores-listadas-na-revista-exame

Lopes, D. V. S. (2020). Avaliação do impacto ambiental e associação entre a exposição à água contaminada e o risco de desenvolvimento de doenças de veiculação hídrica em uma reserva extrativista. 107 f. Dissertação (Mestrado) - Curso de Sociedade, Tecnologias e Políticas Públicas, Universidade Tiradentes, Maceió, Al, Brasil.

Lu, J., \& Li, H. (2020). The impact of government environmental information disclosure on enterprise location choices: Heterogeneity and threshold effect test. Journal of cleaner production. https://doi.org/10.1016/j.jclepro.2020.124055

Marcon, A., Medeiros, J. F., \& Ribeiro, J. L. D. (2017) Innovation and environmentally sustainable economy: identifying the best practices developed by multinationals in brazil. Journal Of Cleaner Production, [S.L.], (160), 83-97. Elsevier BV. http://dx.doi.org/10.1016/j.jclepro.2017.02.101

Miralles-Quirós, J. (2018). The Value Relevance of Environmental, Social, and Governance Performance: the brazilian case. Sustainability, [S.L.], 10(3), 574. MDPI AG. http://dx.doi.org/10.3390/su10030574

Montoto, E. (2018). Contabilidade geral e avançada esquematizado. 5. ed. São Paulo: Saraiva Educação, 1120pp.

Murcia, F. D. R., \& Dos Santos, A. (2009). Fatores determinantes do nível de disclosure voluntário das companhias abertas no Brasil. Revista de Educação e Pesquisa em Contabilidade (REPeC), 3(2), 72-95.

Murcia, F. Da-Ri, Fávero, L. P. L., Rover, S., Lima, G. A. S. F. De, \& Lima, I. (2008). 'Disclosure Verde' nas demonstrações contábeis: características da informação ambiental e possíveis explicações para a divulgação voluntária. Revista UnB Contábil, 11(1-2), 260-278. Recuperado de https://www.revistacgg.org/contabil/article/view/21/49

Nascimento, E. B., Júnior (2018). Reflexos da divulgação de provisões e passivos contingentes ambientais no valor de mercado das empresas de alto potencial poluidor listadas na B3. Curso

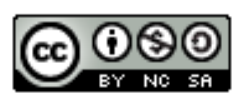


Citação (APA): Souza, J. A. C., de, Machado, B. C. F., Cunha, R. de S., Oliveira, M. C. F., de, \& Oliveira, P. W. S., de. (2021). Análise sobre a divulgação de provisões e passivos contingentes ambientais no valor de mercado das empresas de alto potencial poluidor listadas na bolsa de valores. Brazilian Journal of Production Engineering, 7(5), 65-81.

de Ciências Contábeis - UFB. Trabalho de conclusão de curso. Recuperado de https://repositorio.ufpb.br/jspui/handle/123456789/11929

Nogueira, L. R. T., Curi, M. A., \& Nuintin, A. A. (2012). Relação da rentabilidade e da liquidez com o valor de mercado das empresas brasileiras de capital aberto: estudo do setor de energia elétrica. Revista de Administração da UEG, 8(2). Recuperado de https://www.revista.ueg.br/index.php/revista_administracao/article/view/243

Nossa, V. (2002). Disclosure ambiental: uma análise do conteúdo dos relatórios ambientais de empresas do setor de papel e celulose em nível internacional. Curso de contabilidade. Tese de doutorado, Universidade de São Paulo, SP, Brasil. Recuperado de https://www.teses.usp.br/teses/disponiveis/12/12136/tde-21122005-101506/pt-br.php

Nunes, Z. S. (2021) Análise bibliométrica sobre contabilidade ambiental no período de 20092019.2021. 34 f. TCC (Graduação) - Curso de Ciências Contábeis, Universidade Federal do Tocantins Campus Universitário de Palmas, Palmas - To.

Nelling, E., \& Webb, E. (2009). Corporate social responsibility and financial performance: the "virtuous circle" revisited. Review of Quantitative finance and accounting, 32(2), 197-209.

Odoemelam, N., \& Okafor, R. (2018) The Influence of Corporate Governance on Environmental Disclosure of Listed Non-Financial Firms in Nigeria. Indonesian Journal of Sustainability Accounting and Management, [S.L.], 2(1), 25. Universitas Pasundan Kampus 2. http://dx.doi.org/10.28992/ijsam.v2i1.47

Pien, C.-P. (2020) Local environmental information disclosure and environmental nongovernmental organizations in Chinese prefecture-level cities. Journal of Environmental Management, 275, 111225. https://doi.org/10.1016/j.jenvman.2020.111225

Plastina, E., \& Silveira, E. S. (2017) Análise do cumprimento das exigências de reconhecimento, mensuração e evidenciação das provisões e passivos contingentes em companhias do varejo. Trabalho de Conclusão de Curso - Universidade Federal do Rio Grande do Sul, Porto Alegre. Recuperado de https://lume.ufrgs.br/handle/10183/182982

Plumlee, M., Brown, D., Hayes, R. M., R., \& Marshall, S. (2015). Voluntary environmental disclosure quality and firm value: further evidence. Journal of Accounting and Public Policy, 34(4), 336-361. https://doi.org/10.1016/j.jaccpubpol.2015.04.004

Porter, M. E., \& Kramer, M. R(2006). Strategy and society: The link between competitive advantage and corporate social responsibility. Harvard Business Review, 84(12), 78-92. Recuperado de https://hbr.org/2006/12/strategy-and-society-the-link-between-competitiveadvantage-and-corporate-social-responsibility

Rezaee, Z. (2016). Business sustainability research: a theoretical and integrated perspective. Journal of Accounting Literature, [S.L.], 36, 48-64. Elsevier BV. http://dx.doi.org/10.1016/j.acclit.2016.05.003

Rosa, B. B. da, \& Souza, M. M (2017). Representatividade e nível de evidenciação das provisões e passivos contingentes fiscais nas companhias de capital aberto brasileiras. $7^{\circ}$ Congresso UFSC de Iniciação Científica em Contabilidade, Florianópolis -SC. Recuperado de https://repositorio.ufsc.br/handle/123456789/184503

Rosa, F. S., Ensslin, S. R., \& Ensslin, L. (2009). Evidenciação ambiental: processo estruturado de revisão de literatura sobre avaliação de desempenho da evidenciação ambiental. Sociedade, Contabilidade e Gestão, 4(2), 24-37. https://doi.org/10.21446/scg ufrj.v4i2.13177

Rover, S., Borba, J. A., Dal-Ri Murcia, F., \& Vicente, E. F. R (2008). Divulgação de informações ambientais nas demonstrações contábeis: um estudo estudo exploratório sobre o

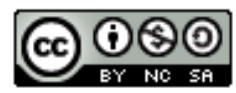

Esta obra está licenciada com uma Licença Creative Commons Atribuição-Não Comercial-Compartilha Igual 4.0 Internacional. Brazilian Journal of Production Engineering, São Mateus, Editora UFES/CEUNES/DETEC. 
Citação (APA): Souza, J. A. C., de, Machado, B. C. F., Cunha, R. de S., Oliveira, M. C. F., de, \& Oliveira, P. W. S., de. (2021). Análise sobre a divulgação de provisões e passivos contingentes ambientais no valor de mercado das empresas de alto potencial poluidor listadas na bolsa de valores. Brazilian Journal of Production Engineering, 7(5), 65-81.

disclosure das empresas brasileiras pertecentes a setores de alto impacto ambiental. Revista de Contabilidade e Organizações, [S. 1.], 2(3), 53-72. https://doi.org/10.11606/rco.v2i3.34713

Rover, S., Tomazzia, E. C., Murcia, F. D., \& Borba, J. A. (2012) Explicações para a divulgação voluntária ambiental no Brasil utilizando a análise de regressão em painel. RAUSP Management Journal, 47(2), 217-230. https://doi.org/10.5700/rausp1035

Rufino, M. A., \& Machado, M. R. (2015). Fatores Determinantes da Divulgação de Informações Voluntária Social: Evidências Empíricas no Brasil. Revista de Educação e Pesquisa em Contabilidade (REPeC), 9(4).

Rufino, M. A., \& Monte, P. A. D. (2015). Fatores que explicam a divulgação voluntária das 100 empresas com ações mais negociadas na BM\&FBovespa. Sociedade, Contabilidade e Gestão, 9(3).

Saeidi, S. P., Sofian, S., Saeidi, P., Saeidi, S. P., \& Saaeidi, S. A. (215). How does corporate social responsibility contribute to firm financial performance? The mediating role of competitive advantage, reputation, and customer satisfaction. Journal of Business Research, 68(2), 341-350. https://doi.org/10.1016/j.jbusres.2014.06.024

Schober, P., Boer, C., Schwarte, L. A. (2018). Correlation Coefficients. Anesthesia \& Analgesia, [S.L.], 126(5), 1763-1768. Ovid Technologies (Wolters Kluwer Health). http://dx.doi.org/10.1213/ane.0000000000002864

Silva, T. S., Carraro, W. B., \& Silva, L. M. (2014) Análise do cumprimento das exigências de reconhecimento, mensuração e divulgação das provisões e passivos contingentes em empresas de mineração, siderurgia e metalurgia. Revista ConTexto, Porto Alegre, 14(27), 89-103.

Silva, V. M., Nascimento, E. B., Jr., \& Araújo, R. A. M. (2018). Reflexos da Divulgação de Provisões e Passivos Contingentes Ambientais no Valor de Mercado das Empresas de Alto Potencial Poluidor Listadas na B3. In: Congresso UFPE De Ciências Contábeis, Não use números Romanos ou letras, use somente números Arábicos., 2018, Pernambuco. Anais [...] . Pernambuco: Ufpe. 3, 1-16.

Solikhah, B., \& Maulina, U. (2021) Factors influencing environment disclosure quality and the moderating role of corporate governance. Cogent Business \& Management, [S.L.], 8,(1), 1876543. http://dx.doi.org/10.1080/23311975.2021.1876543

Sousa, C. B., Silva, A. F., Ribeiro, M. S., \& Weffort, E. F. J. (2014). Valor de mercado e disclosure voluntário: estudo empírico em companhias listadas na BM\&FBOVESPA. Revista Ambiente Contábil - Universidade Federal do Rio Grande do Norte, 6(2), 94-115. Recuperado de: https://periodicos.ufrn.br/ambiente/article/view/4886

Stulz, R. (1990). Managerial discretion and optimal financing policies. Journal Of Financial Economics, [S.L.], 26(1), 3-27. Elsevier BV. http://dx.doi.org/10.1016/0304-405x(90)90011-n

Tang, Y., Yang, R., Chen, Y., Du, M., Yang, Y., \& Miao, X. (2020). Greenwashing of Local Government: The Human-Caused Risks in the Process of Environmental Information Disclosure in China. Sustainability. 12(16), 6329. https://doi.org/10.3390/su12166329

Tzouvanas, P., Kizys, R., Chatziantoniou, I., \& Sagitova, R. (2020). Environmental disclosure and idiosyncratic risk in the European manufacturing sector. Energy Economics, [S.L.], 87, 104715. http://dx.doi.org/10.1016/j.eneco.2020.104715

Zhang, Y., Xing, C., \& Wang, Y. (2020). Does green innovation mitigate financing constraints? Evidence from China's private enterprises. Journal of Cleaner Production, [S.L.], 264, 121698. http://dx.doi.org/10.1016/j.jclepro.2020.121698 